\title{
Research and Countermeasures of Management of the High-Level Overseas Talents
}

\author{
Liangyu Wang \\ Beijing Aeronautical Science \& Technology Research Institute of COMAC, Beijing, China \\ Email: goodjade@163.com
}

Received March 2014

\begin{abstract}
This paper analyzes the very issue of reserving high-level overseas talents in domestic. Reservation of these talents is not just beneficial from local development but it is indeed part of national strategy. Not simple as it seems, the implementation of overseas talents is complex to cope with, which requires agility and patience. We have listed several examples of successful local countermeasures and discussed the main potential problem in introducing high-level overseas talents.
\end{abstract}

\section{Keywords}

\section{High-Level Overseas Talents, Strategy}

\section{Introduction}

Brain circulation is of critical importance to the "giant periphery" of China, which is increasingly seeing its knowledge diaspora as an important resource that is keen to deploy, in the interests of the development of the motherland. But the benefits can be mutual, as highly skilled Chinese help build knowledge bridges between China and their country of residence [1].

In condition of the great technological advancements and deepened economic globalization, we know that whoever takes the talent resources into his hands can keep the lasting development of economics and society. Before the end of the allocation of the talent resources, in China, from the nation to local the government has introduced various policy measures to attract high-level overseas talents to start a business or work in the domestic enterprise, in order to pursue efforts to introduce the talents. In recently, the enthusiasm of the overseas talents to work home is gradually increased, they made a great contribution in improving the domestic technology level, management level, the innovation ability and the adjustment of economic structure. But with the deepening of the introduction, how to use well the talents and how to detain them have become common problems. It also becomes the key of the lasting development of economics and society both nationally and locally.

\section{The Current Situation of Introduction}

The professor of the international institute in Stanford University named Miller pointed that: knowledge econo- 
my is an economy of talent. Talent problem is related to the national comprehensive competitiveness, the value of the talents' creation is far more than which of its input and it has become the consensus in various countries in the word. In today, the most sought-after thing is the human resources with international competitiveness; therefore talent work has been raised to the height of national strategy.

With the aid of globalization, the world has formed a talent market with circulation each other, governments and enterprises are also prompting fierce talent competition [2].

Our country from the center to local has gradually considered the introduction of high-level overseas talents as an important strategic task. Nationally, since reform and opening up, especially in 2008, the General Office of CCCPC (The Central Committee of the Communist Party) proclaimed "the opinion to the high-level overseas talents introduction plan", set the direction and the key point of the introduction. It is a powerful guarantee for overseas talent in China form the system and policy.

\subsection{The Measures to Introduce High-Level Overseas Talents in the Center}

According to "the opinion to the plan of high-level overseas talents introduction", the center, the relevant departments and the local has organized hierarchically the implementation of the high-level overseas talents introduction plan, for short, it is named "The Recruitment Program of Global Experts". For better accomplishment the national development strategy, during 5 - 10 years after 2008 we introduce and give propriety to support a group of strategic scientists and leading talents who can break through the key technology, develop the high-tech industries and drive the emerging disciplines to do pioneering work mainly in the state key innovative projects, in the domain of key disciplines, in the state key laboratory, in the central enterprises and state-owned commercial financial institutions, in the high-tech industry development zone and so on. In eligible state-owned enterprises, universities, scientific research institutions and part of the national high-tech industrial development zone, we established a high-level overseas talents base for promoting the close combination of production, research and learning; exploring ways to establish common international scientific research and technology development and entrepreneurship mechanism; gathering a group of overseas high-level innovative entrepreneurial talent and team. For this task, the central government and the relevant department have seized the opportunity of introduction; intensify efforts to implement the "The Recruitment Program of Global Experts" and have introduced three batch including 662 innovative overseas talents. At present, the fourth batch of "The Recruitment Program of Global Experts" is ongoing. There are a number of world famous scientific and leader of technological innovation included in the introduced overseas talents. The professor, Yishi Chen is one of the founders of the Boltzmann numerical method, is introduced in Beijing University. BUAA has introduced a Russian professor who is the academician of European Academy of sciences, the academician of Russian Academy of sciences and the director of Russian Scientific Research institute of Computation and Simulation. Besides the talents in the science and technology, “The Recruitment Program of Global Experts” has also introduced the high-level talents in management of economy. In general, the introduced high-level overseas talents work in universities, scientific research institutes, enterprises and financial institutions. In those introduced overseas talents, there are 509 innovative talents, 503 ones for starting a startup; 448 ones who have got foreign nationalities and 20 foreigners. There are 293 professors, 9 associate professors and 72 researchers who have worked in Harvard University, Massachusetts institute of technology and Bell laboratory have introduced in China. 75 high-level researchers and 43 high-level managers who have worked in multinational corporations and famous financial institutions have been introduced at home.

The implementation of "The Recruitment Program of Global Experts", has forcefully promoted the introduction work all around the country. Except Xinjiang, Tibet, other provinces have implemented their own plan. In Beijing, there is "Overseas Talents Program"; in Shanghai, there is "one thousand people in Shanghai". Depending on the distribution of the introduced talents, the number of talents in the first six provinces and cities are: Beijing, Shanghai, Jiangsu, Hubei, Guangdong and Zhejiang.

In addition, the ministry of education actively implements the "Cheung Kong Scholars Program". In the recent ten years, 115 institutions of higher learning have recruited 1308 Cheung Kong Scholars, in which 905 are Distinguished Professors and 403 Chair Professors. 90 percent of the Distinguished Professors have overseas study or working experience. The Chair Professors are all recruited overseas. According to China's ministry of education, in 2008 more than 50,000 students abroad returned home which is one times than four years ago. The total number of overseas talents is nearly 32,000, in recent years the number of high-level overseas talents has 
greatly increased.

\subsection{The Current Situation and the Measures of the Introduction in Shanxi Province}

For encouraging and attracting the high-level overseas talents to start a startup, work and serve, for further advancing the strategy of human resources, for promoting the transformation of science and technology innovation achievements into real production forces, for improving the innovative ability in the base and the latest research field, Shanxi has decided starting in 2009 in 5 - 10 years to introduce 200 - 300 high-level overseas talents to work and live in Shanxi.

In addition, Xian has implemented the "plan 5211" to introduce the talents. Starting in 2009, Xian will use near 5 years, divide three levels to do this: according to the central government, introducing 20 high-level overseas talents who meet the "one thousand people plan"; according to Shaanxi province, introducing 100 highlevel overseas talents who meet "one hundred people plan"; according to the development of economy and society of Shaanxi, based on the talents requirement of the "five leading industries", introducing 1000 urgently needed talents in the domain of new and high technology industries, modern equipment manufacturing, tourism, modern service industry, cultural industry, aerospace, biological engineering, new energy, new materials, finance, management and law.

In 2010, Xian has started the "5211 plan" for introducing high-level overseas talents, and would like to attract 1000 talents during five years to live and work in Xian promoting the development of science and economy. For the introduction of Xian, it mainly focuses on the key industry development, the key projects, introduces the urgently needed talents and focuses on the introduction of the overseas high-level innovative talents and teams which do the scientific research, the transformation of scientific and technological achievements, the operation and management and so on. At the same time, Xian should change the mechanism of the relevant departments, construct platform for entrepreneurship, and create a good environment and atmosphere, effectively play a positive role to the construction of Xian international metropolis.

According to the different characteristics of the talent introduction, we adopt special policies and measures, and arrange the work and the treatment of life. For who is very excellent and urgently needed, we even could have one person one policy. We should not only pay attention to the introduction work, but also the management and the service of the ones have introduced in China.

\subsection{The Contribution of the High-Level Overseas Talents to Local Science and Economy}

The high-level overseas talents have made a great contribution to the national and local technology innovation and the transformation of the economic structure. Depending on the statistical data, at present 72 percent of the leaders of the state key projects are overseas talents, 81 percent academician of the Chinese Academy of Sciences and 54 percent academician of the Chinese Academy of Engineering are overseas returnee. In nearly 60 Overseas Students Pioneer Park, there are more than 5000 enterprises with annual output value of more than 10 billion Yuan. In 2006, 67 percent of the first authors of the project of National Natural Science Award Winners are overseas talents; 40 percent of the first authors of State Technological Invention Award are overseas talents; 30 percent of the first authors of National Prize for progress in science and technology project are overseas talents [3].

For the overseas talents, especially the leading talents, it is very important to have a good environment which the policies and the measures can support their career; for the regions in where the government implements the introduction want to attract the talents which are innovative and good for the local development and improve the comprehensive strength. Therefore, we should build National high-tech industrial park, increase capital investment, declare the supporting policies, and optimize the environment of innovative undertaking and so on. The attracted talents always have the innovative achievements and independent intellectual property rights with modern management philosophy and are good at operating resources. They can promote the construction of the local and because of this it will attract more and more high-level overseas talents. At the same time, they are the key to break through the technological difficulty, improve the high-tech industries and are very important to some emerging disciplines. They play an important role in the promoting the local Science and technology innovation ability and the upgrading of industrial structure. In a word, introduction of the overseas talents is the right decision no matter for national or local technology and economy; it will promote economic and social development rapidly and soundly; it is very important for building a well-off society in an all-round way, besides it 
will establish talent competition advantage, and enhance core competitiveness.

\section{The Main Problem of the Introduction of High-Level Overseas Talents}

The former minister of commerce has said that "just as the company recruits the best employees, universities admit the best students; our state will do our best to detain the leading talents". In those days the introduction work is effective, but how to adapt to the structure of the industry and how to detain the talents have become the common problems. For example, in some regions, the introduction work was regardless the local condition with certain blindness; they over emphasized the number, but they did not consider the overall condition and overall plan which made the introduced talents had not the appropriate situations and the ones which the local really needed were not introduced. Some of the overseas talents did not succeed in starting a business and some overseas returnees had to return board [4].

For how to introduce, retain and use, the Jiangsu Zhejiang Shanghai area has some successful practices. For example, the "Pujiang talent plan" in Shanghai, the government has input 40 billion every year to fund the person and the team which return to Shanghai to work and live; Changzhou give 1 - 4 billion to the overseas returnee. Jiangsu, Zhejiang and Shanghai have strengthened the construction of the startup hub for the overseas talents to create professional platform for the introduction of overseas talents. In Zhejiang, it formed a pioneer park which Hangzhou, Ningbo, Wenzhou is considered as the center and they will drive all the pioneer parks in the whole province including Hangzhou, Ningbo, Wenzhou, Huzhou, Shaoxin, Jinhua, those 7 national pioneer park and Ningbo, Jiaxin those two local pioneer park. Offering well qualified and considerable service is a very important issue in entrepreneurship for talents [5]. In Changzhou, we have founded "platform of financing for enterprises founded by oversea talents" to assure 30 million Yuan as financing, to help with financial difficulty in initial stage; we've also founded "Card for oversea talents of Changzhou”, including social insurance, technology, national tax, landed duty etc. in total 10 green channels of service, all destined for better service on oversea talents who have ambitions to make business.

\section{Management Strategy and Suggestion of High-Level Oversea Talents}

\subsection{Introducing Respective Talents to Respective Sector in Order to Adapt to the Mutation of Industry Structure}

Though some places have already valid many kinds of policy, and they truly have attracted a lot of high-level oversea talents. But governments have ignored the whole structure of industry, causing excessive talents in certain sector meanwhile the very lack of high qualified labor is still there. Therefore, we must have in mind "scientific development" with introducing oversea talents and consider the industry structure and local need in talents. In this way, we have our talents filtered and better used. If possible, we can rely on high-tech exploring center, park of oversea talents' enterprises, university technological park etc. to attract oversea talents.

\subsection{Government Must Solve Oversea Talents' Problem}

Some oversea talents come back to start their own enterprises with only a few ideas, several patents or technological achievements, however, financial problem is the biggest problem. Direct funding of government cannot hold long and there are few organizations to finance for oversea enterprises [6]. Therefore, the government must change its view by helping these organizations to finance more, by caring about talents' difficulty, such as immigration issues, lodgment, children's education, insurance etc., to make them at home, help them out, and then help them to concentrate on innovation or business.

\subsection{Preferential Policy's Slope}

Example of Jiangsu province is worth a look: To attract more oversea talents to come to Jiangsu province to make business, on July 13th 2011, the government has valid "policy of residence permit for oversea talents". By this policy, residence permit is parallel to identity card and preferential policy. This has helped out their problems in life as well as them in business. After this policy, oversea doctors who meet the demands can get a resident permit signed by local government. With the permit, we can get funds, children's education, business license etc. in total 14 policies. So far there are more than 50 thousand overseas making businesses in Jiangsu. 


\subsection{Establishment of Good Mechanism for Introducing, Keeping and Using}

Introducing talents is a long term mechanism. We must take it as a long term strategic engineer. For achieving this goal, we should establish good mechanism for introducing, keeping and using. On introduction, we must pay attention to policy, environment, emotion and salary issues, exploring the giant market of oversea talents. Introduce them, keep them and make full use of them [7]. By having "honor knowledge, respect talents, encourages business" in mind, we hope to have talents coming, functioning and achieving in the end local sustainable development.

\section{Conclusion}

With discussions above, we can but conclude the complexity of this implementation. We observe that countermeasures that have certain success must adapt to local commercial and social situation and they all need strengthened support of local government. Therefore, this is a local government issue rather than something that can be adaptable anywhere. By analyzing and learning from existing countermeasures, we can develop other countermeasure in other regions of China.

\section{References}

[1] Welch, R. and Zhen, W. (2008) Higher Education and Global Talent Flows: Brain Drain, Overseas Chinese Intellectuals and Diasporic Knowledge Networks. Higher Education Policy, 21, 519-537. http://dx.doi.org/10.1057/hep.2008.20

[2] Zweig, D. (2006) Competing for Talent: China’s Strategies to Reverse the Brain Drain. International Labour Review, 145, 65-90.

[3] Denis, F.S. and Cao, C. (2009) China's Emerging Technological Edge. Cambridge University Press, Cambridge.

[4] Dong, Y.X. (2009) The Theoretical and Empirical Study on the Overseas Talent Introduction in China.

[5] Ben, Y.L. Introduction of Overseas Talents: A Way to Be Nationally Strong.

[6] Lili, W. and Deyan, L. (2005) Innovation for High-Level Overseas Talents Introduction in China.

[7] Machuan, F. (2003) The Space That Overseas Talents Have in China. 